\title{
Muscle Mass Difference among Patients With Chronic Kidney Disease Stage 3 to Stage 5
}

\author{
Ivena, ${ }^{1}$ Rudi Supriyadi, ${ }^{2}$ Setiawan $^{3}$
}

${ }^{1}$ Faculty of Medicine Universitas Padjadjaran, Indonesia, ${ }^{3}$ Department of Internal Medicine Faculty of Medicine Universitas Padjadjaran/Dr. Hasan Sadikin General Hospital Bandung, Indonesia,

${ }^{2}$ Department of Biomedical Sciences Faculty of Medicine Universitas Padjadjaran, Indonesia

\section{Abstract}

Background: Low muscle mass is one of the complications of chronic kidney disease (CKD), that may occur due to the accumulation of uremic toxins and other mechanisms related to CKD. The aim of this study was to explore the difference of muscle mass among CKD patients stage 3 to stage 5 .

Methods: A cross-sectional study was conducted with comparative analysis, using secondary data collected during the year 2017 by total sampling method. Subjects were patients aged over 18 years with CKD stage 3 to stage 5 from three hospitals in Bandung. Chronic Kidney Disease stages were determined based on Glomerular Filtration Rate. Muscle mass data was determined using Bioelectrical Impedance Analysis, collected from previous research. Data were analyzed usingone-way ANOVA or Kruskal-Wallis test.

Results: One hundred subjects consisting of 57 men and 43 women were included in in this study with the mean muscle mass was $26.29 \% \pm 4.86$, of whom $67 \%$ of the patients had low muscle mass. There was no difference between male $(27.21 \% \pm 3.82)$ and female $(28.36 \% \pm 4.67)$. The muscle mass among patients withCKD stage 3 to stage 5 showed no significant results ( $p>0.05)$.

Conclusions: There is no difference in muscle mass among CKD stage 3 to stage 5.

Keywords: Chronic kidney disease, glomerular filtration rate, muscle mass

\section{Introduction}

Chronic Kidney Disease (CKD) is defined as abnormalities of kidney structure or function for 3 months or more. ${ }^{1}$ CKD has a high and consistent global prevalence., ${ }^{2,3}$ It is estimated that the prevalence ofCKD is between 11 to $13 \%$ with the majority CKD is in stage 3. Millions of people have died from its complications each year. ${ }^{2,3}$ It is also ranked as the $17^{\text {th }}$ leading cause of global years of life lost, and the third largest increase of any major cause of death. ${ }^{4}$ Based on National Basic Health Research (Riset Kesehatan Dasar, Riskesdas) 2013, the prevalence of CKD in Indonesia has increased with age, with a peak in the age above 75 years old. ${ }^{5}$

Generally, CKD stage 1 and 2 show no clinical signs and symptoms, although a decrease in GFR has occurred. ${ }^{6}$ In advanced stage of CKD, clinical signs and symptoms may appear as a manifestation of declined filtration function. This may also cause some complications. ${ }^{1,6}$
One of its complications is a decrease in muscle mass that occurs along with advancing stage of CKD. ${ }^{6}$ Low muscle mass can occur due to metabolic acidosis, insulin resistance, inflammation, and increased glucocorticoid production and angiotensin II in CKD patients. These conditions can activate catabolic pathways such as Ubiquitin-Proteasome System (UPS), caspase-3, lysosomes, and myostatin in protein degradation. ${ }^{7,8}$ Decrease muscle mass and muscle streng this associated with high risk of heart failure, fractures, infections, frailty, and insulin resistance. ${ }^{9}$ The reduction in muscle mass shows a higher risk of death. ${ }^{10}$ Disability, morbidity and even mortality can occur as a manifestation of comorbid complications of low muscle mass and muscle strength. ${ }^{9}$ The Healthcare and Social Security Agency (Badan Penyelenggara Jaminan Sosial Kesehatan, BPJS) in Indonesia shows that CKD treatment costs is placed second for health funding after heart disease, ${ }^{1}$ therefore, from an economic and clinical

Correspondence: Ivena, Faculty of Medicine, Universitas Padjadjaran, Jalan Raya Bandung Sumedang Km. 21 Jatinangor, Sumedang Indonesia, Email: ivena15001@mail.unpad.ac.id 
perspective, prevention on CKD progression is required for further complications. ${ }^{12}$

Research on CKD and muscle atrophy has been widely carried out, however, no studies have discussed about differences in muscle mass for each stage of CKD. This study aimed to explore the muscle mass differences among CKD stages.

\section{Methods}

The design of this study was a cross-sectional with comparative analysis, conducted from April to August 2018 using secondary data from previous studyin 2017. Data were collected from three hospitals in Bandung, that were in Dr. Hasan Sadikin General Hospital, Dustira Hospital, and Kidney Special Hospitals Ny. R.A. Habibie. This study had been approved by the Health Research Ethics Committee Universitas Padjajaran Bandung (No.294/ UN6.KEP/EC/2018).

In brief, data from all patients aged over 18 years with CKD stage 3 to stage 5 who had not undergone hemodialysis were collected. Data of patients with malignancy, infectious diseases, severe diseases or patients who routinely consumed antioxidants, and patients with incomplete data that did not include the variables sought including muscle mass and GFR, were excluded. The collected data were grouped according to the stages of CKD i.e. stage 3 , stage 4 , and stage 5 , based on the GFR in accordance with KDIGO 2012 Clinical Practice Guidelines for Evaluation and Management of Chronic Kidney Disease. ${ }^{1}$

Skeletal muscle mass were measured using Bioelectrical Impedance Analysis (BIA). Measurements of muscle mass were performed in various body regions, namely trunk, upper limb, lower limb, and the whole body. Muscle mass data were also grouped into 4 categories: low, normal, high, and very high, ${ }^{13}$ and compared between age group and gender. Muscle mass were expressed in terms ofa ratio between muscle mass and body weight. ${ }^{13}$

One-way ANOVA statistical test was conducted to explore the differences in muscle mass among CKD stages when the data were normally distributed or otherwise Kruskal-Wallis statistic test when the data was not normally distributed. Furthermore, post-hoc analysis was performed to assess the comparison between groups. Hypothesis tests were considered significant if the value of $\mathrm{p}<0.05$. Multiple linear regression analysis was also conducted to control confounding variables. Data analysis was conducted using IBM SPSS Statistics v.23.

\section{Results}

In total, 100 data of CKD patients that was met the criteria was collected. The characteristics of the CKD patients were grouped according to the stage of CKD (Table 1). Most of patients were found to be male; however, there was no significant correlation between gender and CKD stages $(p=0.765)$. As for age, stage 4 CKD patients were found to be older compared to CKD stage 3 , in which it had the lowest median age of 54 years, and there was a significant age difference among CKD stage $3-5(\mathrm{p}=0.002)$. Furthermore, no significant difference in BMI among CKD stage 3-5 ( $p=0.067)$.

The muscle mass in patients with CKD stage 3 to stage 5 was presented in Table 2 . Measurements of muscle mass were performed in various body regions. Overall, there was an increase in muscle mass with the stage of CKD,

Table 1 The Characteristicsof Chronic Kidney Disease patients based on Stages

\begin{tabular}{lcccc}
\hline & \multicolumn{3}{c}{ Chronic Kidney Disease } \\
& $\begin{array}{c}\text { Stage 3 } \\
\text { (n=21) }\end{array}$ & $\begin{array}{l}\text { Stage 4 } \\
\text { (n=34) }\end{array}$ & $\begin{array}{c}\text { Stage 5 } \\
\text { (n=45) }\end{array}$ & P Value \\
\hline $\begin{array}{l}\text { Gender, n (\%) } \\
\quad \text { Male }\end{array}$ & $11(52.38)$ & $21(61.76)$ & $25(55.56)$ & 0.765 \\
$\quad$ Female & $10(47.62)$ & $13(38.24)$ & $20(44.44)$ & \\
$\begin{array}{l}\text { Age (years), median } \\
\text { (min-max) }\end{array}$ & $54(24-69)$ & $65(28-77)$ & $59(33-78)$ & $0.002^{*}$ \\
$\begin{array}{l}\text { BMI (kg/m2),median } \\
\text { (min-max) }\end{array}$ & $23.75(17.65-37.99)$ & $24.39(18.75-36.36)$ & $22.11(10.54-35.39)$ & 0.067 \\
\hline Note: BMI= Body Mass Index & & & & \\
\hline
\end{tabular}

Note: BMI $=$ Body Mass Index 
Table 2 Muscle Mass in Chronic Kidney Disease Stage 3-5 Based on Gender

\begin{tabular}{lcccc}
\hline \multicolumn{1}{c}{ Muscle mass (\%) } & Stage 3 & Stage 4 & Stage 5 & P Value \\
\hline Whole body & $26.29 \pm 4.86$ & $27.21 \pm 3.82$ & $28.3 \pm 4.67$ & 0.188 \\
Male & $28.5(21.8-35.1)$ & $28.3(18.3-37.8)$ & $29.5(16.0-39.2)$ & 0.598 \\
Female & $23.19 \pm 2.82$ & $25.25 \pm 2.99$ & $26.99 \pm 4.67$ & $0.046^{*}$ \\
Trunk & $18.9(13.6-30)$ & $20.5(12.5-33.6)$ & $23.6(10.8-34.4)$ & 0.071 \\
Male & $23.7(13.6-30)$ & $21.9(17.2-33.6)$ & $23.8(17.9-34.4)$ & 0.553 \\
Female & $17.53 \pm 2.60$ & $18.72 \pm 3.01$ & $21.16 \pm 5.04$ & 0.055 \\
Upper Limb & $30.4(20.5-39.9)$ & $33.8(13.5-41.3)$ & $34.9(18.7-48.5)$ & $0.037^{*}$ \\
Male & $35.0(21.0-39.9)$ & $34.4(19.9-41.3)$ & $36.3(30.4-42.9)$ & 0.591 \\
Female & $25.66 \pm 3.96$ & $27.25 \pm 5.59$ & $31.86 \pm 7.52$ & $0.027^{*}$ \\
Lower Limb & $40.9(30.1-52.3)$ & $44.15(34.5-54.9)$ & $45.1(25.0-77.3)$ & 0.245 \\
Male & $45.9(36.4-52.3)$ & $45.80(34.8-54.9)$ & $46.9(42.4-77.3)$ & 0.376 \\
Female & $35.78 \pm 3.77$ & $39.19 \pm 3.6$ & $39.44 \pm 6.86$ & 0.203 \\
\hline
\end{tabular}

Note: $\mathrm{CKD}=$ Chronic Kidney Disease. ${ }^{*}$ p value $<0.05$ considered to be significant different among the groups

although the difference was not significant, except in the upper limb as shown in Table 2. Interestingly, not only the whole body'smuscle mass in female showed a significant increase with the stages $(\mathrm{p}=0.046)$,but also in the upper limb's muscle mass $(\mathrm{p}=0.027)$.

The result of the multiple linear regression tests to control confounding variables was shown in Table 3. After the multivariate test was performed to control confounding variables (BMI and age), the result showed similar results; there was no significant difference in muscle mass among male subjects with CKD stage 3 to stage $5(p=0.565$ and $p=0.422)$. Interestingly, there was a significant difference $(p=0.032$ and $p=0.021)$ in female subjects. The classical assumption test showed that there was no multicolinearity and error distribution and this had not followed normal distribution pattern. Transformation of the dependent variable was needed, so the error distribution followed the normal distribution pattern.

\section{Discussion}

Chronic kidney disease is predominantly in male, and in our study, aged above 50 years. It is more common in older age due to a decline in renal function with increasing age and due to the presence of various risk factors of CKD in older individuals such as diabetes and

Table 3 Multiple Linear Regression Analysis with Muscle Mass as the Dependent Variable

\begin{tabular}{|c|c|c|c|c|c|c|c|c|}
\hline \multirow{3}{*}{$\begin{array}{l}\text { Predictor } \\
\text { Variables }\end{array}$} & \multicolumn{4}{|c|}{ Male } & \multicolumn{4}{|c|}{ Female } \\
\hline & \multirow[t]{2}{*}{ Value } & \multirow[t]{2}{*}{ P Value } & \multicolumn{2}{|c|}{$\begin{array}{c}\text { Confidence Interval } \\
95.0 \%\end{array}$} & \multirow[t]{2}{*}{$\beta$ Value } & \multirow[t]{2}{*}{$P$ Value } & \multicolumn{2}{|c|}{$\begin{array}{c}\text { Confidence Interval } \\
95.0 \%\end{array}$} \\
\hline & & & Minimum & Maximum & & & Minimum & Maximum \\
\hline Constant & 3.545 & 0.000 & 3.091 & 3.999 & 3.723 & 0.000 & 3.400 & 4.046 \\
\hline Stage 4vs. 3 & 0.040 & 0.565 & -0.097 & 0.176 & 0.119 & $0.032 *$ & 0.011 & 0.228 \\
\hline Stage 5vs. 3 & 0.049 & 0.422 & -0.072 & 0.170 & 0.119 & $0.021^{*}$ & 0.019 & 0.219 \\
\hline Age & 0.004 & 0.129 & -0.009 & 0.001 & -0.006 & $0.002^{*}$ & -0.009 & -0.002 \\
\hline BMI & 0.001 & 0.820 & -0.009 & 0.011 & -0.011 & $0.025^{*}$ & -0.021 & -0.002 \\
\hline
\end{tabular}

Note: Dependent Variable = Muscle Mass (Whole Body); BMI=Body Mass Index 
hypertension. ${ }^{14}$

After stratifying the data into male and female, the result shows that there is no significant difference in whole body's muscle mass on male subjects; whereas in female subjects there is a significant difference in whole body's muscle mass. No differences in male subjects may occur due to almost all male subjects who have low muscle mass since stage 3 CKD. The difference in whole body's muscle mass has been shown in female subjects with stage 3 and stage 5 CKD. Statistically, a significant difference in muscle mass of female subjects does not correlate with clinical sign due to a high number of female subjects with low muscle mass. Several other factors such as physical activity, nutritional intake, hormonal status, and menopausal status may cause differences in subjects' muscle mass. This may be due to more daily activities involving the upper and lower extremities. The whole body's muscle mass may also be affected by low muscle mass in the trunk region. A significant difference in muscle mass has also been found in the female's upper limb area ( $p=0.027)$, next to an increase in muscle mass with increasing stage of CKD. This phenomenon has not been clearly explored and need further study.

A decrease in muscle mass can occur along with a declinein kidney function, as confirmed this study. ${ }^{10}$ As the CKD stage increases, kidney filtration function will decline. ${ }^{1}$ This condition may cause accumulation of substances that should be excreted through the kidneys. Accumulation of uremic toxins may lead to a variety of clinical symptoms and complications. ${ }^{6,15}$ Complications that may arise from the accumulation of uremic toxins include the degradation of muscle protein. This may happen due to the increase of ubiquitin and proteasome transcription, resulting in an increase in protein degradation that may cause loss of muscle protein in CKD patients. ${ }^{16,17}$ Chronic Kidney Disease stage was also classified based on kidney ability to filter various toxins, the lower the kidney filtration function (higher CKD stage), the higher the amount of toxins that involved in activation of muscle protein degradation process. ${ }^{1,6}$ Muscle protein degradation was a resultof various mechanisms involving uremic toxins such as metabolic acidosis, insulin/IGF-1 signaling, inflammation, decreased hypothalamic function in regulating appetite, and micro RNA deregulation. All of these conditions may lead to the activation of UPS, caspase-3, lysosome and myostatin pathways in muscle protein catabolism. ${ }^{16}$ These conditions may cause an imbalance between protein synthesis and protein degradation, so that there may be a decrease in muscle mass and muscle strength. Loss of appetite may also be caused by a decrease in hypothalamic function. This may also trigger a decrease in muscle mass due to reduced protein intake. Disability, mortality and even mortality may occur as a manifestation of comorbid complications of lowmuscle mass and muscle strength. ${ }^{9}$

This study showed that low muscle mass had been found from stage 3 CKD, however, this study did not measure muscle mass in stage 1 and stage 2 since no clinical signs and symptoms can be observed, even though there is a decrease in GFR. ${ }^{6}$ Prevention of low muscle mass in CKD patients could be done by among others giving supplementation in the form of essential keto acids and amino acids that are safe for the kidneys to prevent further decline in muscle mass, regulation of nutritional intake with a low protein diet that is appropriate for the needs of each CKD stage, ${ }^{9,18}$ and examination of muscle mass and body composition and doing routine and controlled physical activity are also recommended to prevent CKD progression even to reduce the risk of death due to loss of muscle mass. ${ }^{9}$ By preventing a decrease in muscle mass and strength in CKD patients, the progression of CKD canbe prevented. If these things weredone,the risk of heart failure, fractures, infections, muscle weakness, and insulin resistance can also be prevented. ${ }^{9}$ Furthermore, the high number of CKD patients with low muscle mass suggests that physical activity is needed. We here to recommend exercise in CKD patients as a structured activity that includes aerobic exercise, which uses large amounts of oxygen for example strength training, which involves using a large amount of muscle; and flexibility training, which involves joint activity. ${ }^{19}$

The limitations of this study are unmeasured factors that may affect muscle mass. These factors include data on nutritional intake, hormonal status, menopausal status, and physical activity. Confounding variables in this study are controlled through data analysis and data stratification only. Another limitation of this study is that the data cannot be excluded from chronic diseases that may have been preceded CKD. One chronic disease that may become the etiology of CKD is diabetes mellitus. Diabetes mellitus may affect muscle mass variables in the study subjects. Thus, further research is needed by paying attention 
to and taking into account other factors that can affect muscle mass in CKD patients.

To conclude, no difference in the whole body's muscle mass in male patients with chronic kidney disease stage 3 to stage 5; in opposite, female patients subjects with stage 3 to stage 5 CKD. The low muscle mass found since stage 3CKD indicates that the examination of muscle mass, regulation of protein intake and supplementation of nutrients according to patient's needsare important.

\section{References}

1. Eknoyan G, Lameire N, Eckardt K, Kasiske B, Wheeler D, Levin A, et al. KDIGO 2012 clinical practice guideline for the evaluation and management of chronic kidney disease. Kidney Int Suppl. 2013;3(1):1-150.

2. Hill NR, Fatoba ST, Oke JL, Hirst JA, O'Callaghan CA, Lasserson DS, et al. Global prevalence of chronic kidney disease - A systematic review and meta-analysis. PLoS One. 2016;11(7):e0158765.

3. World Kidney Day. Chronic kidney disease. 2018. [cited 2018 August 5]. Available from: http://www.worldkidneyday.org/ faqs/chronic-kidney-disease/.

4. GBD 2015 Mortality and Causes of Death Collaborators. Global, regional, and national life expectancy, all-cause mortality, and cause-specific mortality for 249 causes of death, 1980-2015: a systematic analysis for the Global Burden of Disease Study 2015. Lancet. 2016;388(10053):1459-544.

5. Kementrian Kesehatan Republik Indonesi. Pusat data dan informasi kementrian kesehatan republik indonesia: situasi penyakit ginjal kronis. Jakarta: Kementrian Kesehatan Republik Indonesia; 2017.

6. Kasper DL, Fauci AS, Hauser SL, Longo DL, Jameson JL, Loscalzo J. Harrison's principles of internal medicine. 19th Ed. New York: McGraw Hill Education; 2015.

7. Wang $\mathrm{XH}$, Mitch WE. Muscle wasting from kidney failure-a model for catabolic conditions. Int J Biochem Cell Biol. 2013;45(10):2230-8.
8. Wang DT, Yang YJ, Huang RH, Zhang ZH, Lin X. Myostatin activates the ubiquitinproteasome and autophagy-lysosome systems contributing to muscle wasting in chronic kidney disease. Oxid Med Cell Longev. 2015;2015:684965.

9. Stenvinkel P, Carrero JJ, von Walden F, Ikizler TA, Nader GA. Muscle wasting in end-stage renal disease promulgates premature death: established, emerging and potential novel treatment strategies. Nephrol Dial Transplant. 2016;31(7):1070-7.

10. Oliveira EA, Cheung WW, Toma KG, Mak RH. Muscle wasting in chronic kidney disease. Pediatr Nephrol. 2018;33(5):789-98.

11. Couser WG, Remuzzi G, Mendis S, Tonelli M. The contribution of chronic kidney disease to the global burden of major noncommunicable diseases. Kidney Int. 2011;80(12):1258-70.

12. Olivier J. Wouters, Donal J. O'Donoghue, James Ritchie, Panos G. Kanavos, Narva AS. Early chronic kidney disease: diagnosis, management and models of care. Nat Rev Nephrol. 2015;11(8):491-502.

13. OMRON HealthCare. Instruction manual: body composition monitor HBF-375. Kyoto, Japan: OMRON Healthcare Co.,Ltd; 2012.

14. Prakash S, O'Hare AM. Interaction of aging and chronic kidney disease. Semin Nephrol. 2009;29(5):497-503.

15. McCance KL, Huether SE. Pathophysiology: the biologic basis for disease in adults and children. 7th ed. St. Louis, Missouri: Elsevier; 2013.

16. Wang XH, Mitch WE. Mechanisms of muscle wasting in chronic kidney disease. Nat Rev Nephrol. 2014;10(9):504-16.

17. Rajan VR, Mitch WE. Muscle wasting in chronic kidney disease: the role of the ubiquitin proteasome system and its clinical impact. Pediatr Nephrol. 2008;23(4):527-35.

18. Mitch WE, Remuzzi G. Diets for patients with chronic kidney disease, should we reconsider? BMC Nephrol. 2016;17(1):80.

19. Milam RH. Exercise guidelines for chronic kidney disease patients. J Ren Nutr. 2016;26(4):e23-5. 